\title{
11 Artists on Braille Babbles: A Catalogue
}

\section{Chantal Durand L'éloge de l'ombre}

The artist found her inspiration in the title In Praise of Shadows by Japanese author Jun'ichiro Tanizaki, a study on light, clarity and how the different nuances of darkness literally highlight small objects in various shades of dazzling, shiny or gleaming effects. Chantal Durand's piece reflects on Tanizaki's poetics of chiaroscuro. It emboldens the most humble object, like this thimble protecting fingertips from being hurt or pricked, at the same time as it gives it a soft volume. Hers is a luxurious meditation on seeing and not seeing and how intricate they are. (CP)

\section{Never Lopez Cipher}

Never Lopez's artistic practice is cryptic in nature. Just as in his artist's book Lite Sweat Crude, Cipher offers a coded image - a chessboard maybe, on which strategic positions appear in illusory raised dots. These false raised dots are the message that we need to reconstruct and figure out of this non-figurative riddle. The abstraction is double and unlikely to find a resolution. For one, its embossments in trompe-l'oeil form an unreadable braille; the surface of the piece is smooth and no fingertips will explore the shape of these dots whose visible shadows do not correspond to any asperity. Furthermore, for those of us who do not use their fingertips to perceive white dots, no key to the code is provided, while the message is too short to create patterns, thus securing secrecy. To the riddle of the cipher, only one answer is possible: it is a cipher. (CP)

\section{Daniel F. Manchego-Badiola Weary Wanderers series}

2013

Silver gelatin print

9 " $x 12.5$ " each

"There is something to be said about the vast array of inscrutable layers life has to offer: We all wonder and wander at times in hopes that we can shed the burden of its mysteries. I, for one, have been in a pensive state of late, and can't help but feel a disconnect from this weighted reality. Like the spectral wanderers, I too contemplate the need for a purpose and to divest oneself of the binds of memory; stuck in a limbo of transcendence. Through my travels and experiences I continue to seek a sort of clairvoyance, and although it's a difficult state to climb to, the realization of these weary wanderers was another step in my ascension." (DMB) 


\section{Marinko Blind}

\section{Vision}

Marinko's visual creation functions both as a title and as a keyword for the narrative poem it accompanies. If we ever doubted that skateboards could tell a story, lively, fluid, as graceful as skateboarding is, we will certainly revise our opinion. Despite their slick composition (sober colours, sober background, simple words in braille), the brailled skateboards allow us to move rapidly and follow a complex train of thoughts on growing up, emigration, languages and communication, vision and free-wheeling liberty. Braille is the (pre) text to flowing storytelling. $(\mathrm{CP})$

\section{Arnold McBay}

Impossibility, 1914 to 2013

January 14, 2013

Text, photoshopped digital photograph. Output size 12" high x 16" wide

300dpi

"The visual object in this digital submission features an embedded/obscured text which reads as follows:

I sought words, haltingly, in order to describe the night but their slippery surfaces resisted my touch. Through them I hoped to trace the past and somehow feel the grain of time. Strange how the night gives me a sense of emptiness and fullness at the same time. Are these words as barren as I feel, as full?

Through the juxtaposition of image and text, elements which threaten to cancel each other out, this project probes the limits of textual and image representation. Through the conflation of image with text (or text with image?) one wonders if there is any structure, or merely a visual space for the viewer/reader to contemplate the collision therein." (AMB)

\section{Stephen Remus}

OMADHAUN*ALL

"Two words: OMADHAUN*ALL

Spelled using a once popular card game from the 1930s called Lexicon.

The words are a conflation of Gaelic/Ottawa Valley slang meaning something along the lines of, 'everyone's become simpletons'.

They're superimposed over images that are the results of instruction manuals on how to make portraits." (SR) 
Eric Schmaltz

Four visual poems from MITSUMI. ELEC. CO. LTD.

Paint, disassembled computer keyboard, photoshop

"While these poems don't engage directly with braille itself, the poems do at some level engage with ideas and questions regarding of language's materiality, tactility, and the language devices we use to creatively communicate. The poems I have presented here have been created by painting the parts of a disassembled keyboard and dragging / imprinting / dropping / rolling / smearing these painted parts onto card stock. In some cases, I left resulting images untouched while others were manipulated via image editing tools. I have offered examples of each tactic." (ES)

\title{
Ramona Schnekenburger Rehkitz
}

2013

$60 \times 80 \mathrm{~cm}$

Öl auf Leinwand (oil on canvas)

This drawing visualizes an exquisite tactility. Like the almost erased figure, we would like to hold the deer gently and, maybe, also its frailty and its entire trust in these protective, respectful hands. The moment is one of intense yet pristine sensuousness. We can almost feel the tenderness instilled in the small animal. Here speaks the fullness of delicate touch. (CP)

\section{Shawn Serfas}

\author{
Portrait of Mark, Plaything Series \\ Tent and Tree, Plaything Series
}

Both 2013

Acrylic on Canvas

$33 \mathrm{~cm} \times 33 \mathrm{~cm}$ (13 inches $x 13$ inches)

Tactile language may be textile. In textile there is text, textuality, texture, intertextuality, something woven, something written, here in stripes stripped of any textual message, invoking simply the thread-work of word-writing. Rendered in flourishing acrylic colours, these textiles tell us about home and its daily warmth. (CP) 
Joël Therrien

2013

Plywood, inkjet prints on cotton, cotton thread, steel bearings, red light bulb, electrical box, grounded wire, aluminum, cotton mill bobbin, nails, screws, stain, varnish; 69 1/2"x 28 " $x 28$ ",

"My current body of work examines my Franco-Ontarian heritage as well as Welland's francophone community in relation to the historic Empire Cotton Mills, Limited. My research has focused primarily on the emergence and the relatively recent decline of Southern FrancoOntarian communities. This phenomenon is mirrored by the inherent entropy of my interactive works. My gravitation towards creating interactive works has also been to invite the viewer to breach gallery decorum and evoke in them a sense of play. This is exemplified through pieces such as La filature cotonnière qui a tissé une communauté, wherein the viewer is asked to physically engage with the work in order to be rewarded by a light driven animation of hand drawn cotton being fed through various schematics of cotton mill machines, which in turn produce a "ceinture fléchée," a traditional francophone garment. Additionally, the schematics of the cotton mill machines have been printed onto cotton sheets which have been sewn together to form a continuous loop. This, in addition to the retired cotton mill bobbin which is used as a handle to activate the device, provides the viewer with a tactile experience of the work which is further reinforced by the mechanistic sound that is produced once the viewer begins to interact with the piece. My objective when creating this most recent body of work has been to achieve seemingly sophisticated effects using simple mechanical processes." (JT)

\section{Eric Zboya}

\section{Untitled \#1, for Derek Beaulieu \\ Untitled \#2, for Derek Beaulieu Ascorbic Acid \#2 \\ DHA \#2 \\ Retinol Constellation}

"The first two pieces, entitled 'untitled \#1, for derek beaulieu' and 'untitled \#2, for derek beaulieu,' illustrate two braille-rendered translations of two visual poems by visual poet derek beaulieu.

The next three pieces, entitled 'ascorbic acid,' 'dha \#2,' and 'retinol constellation,' showcase the molecular structures of ascorbic acid, DHA (docosahexaenoic acid), and retinol respectively, but rendered in the braille code. Ascorbic acid, DHA, and retinol all share one commonality - they help in the prevention of cataracts, glaucoma, retinal disorders, and macular degeneration, or, diseases that cause blindness. We have the ability to delineate the structures of organic compounds, and we have the ability to manipulate elements to create the structures of synthetic compounds; however, we lack the technological ability to see each individual atom that creates these molecular compositions, which is why 'ascorbic acid,' 'dha \#2,' and 'retinol constellation' have been reconstructed in braille." (EZ)

(CP) - Catherine Parayre 